\title{
Correction to: Sulfonylureas in the Current Practice of Type 2 Diabetes Management: Are They All the Same? Consensus from the Gulf Cooperation Council (GCC) Countries Advisory Board on Sulfonylureas
}

Yousef Al-Saleh (D) - Shaun Sabico • Ahmed Al-Furqani · Amin Jayyousi · Dalal Alromaihi • Ebtesam Ba-Essa • Fatheya Alawadi · Juma Alkaabi • Mohamed Hassanein · Saud Al-Sifri • Seham Saleh • Thamer Alessa • Nasser M. Al-Daghri

Published online: July 23, 2021

(C) The Author(s) 2021

Correction to: Diabetes Ther https://doi.org/10.1007/s13300-021-01059-1

In the Original Article, the author affiliations were incorrectly published. Please find the correct affiliations as given below.

\section{A. JAYOUSSI}

Endocrine and Diabetes Section, Hamad Medical Corporation, Doha, Qatar

Weill Cornell Medical College, Doha Qatar

The original article can be found online at https://doi. org/10.1007/s13300-021-01059-1.

Y. Al-Saleh $(\bowtie)$

College of Medicine, King Saud Bin Abdulaziz

University for Health Sciences, Riyadh 22490, Saudi

Arabia

e-mail: salehy1@ngha.med.sa

Y. Al-Saleh

King Abdullah International Medical Research

Center, Riyadh 11481, Saudi Arabia

Y. Al-Saleh

Department of Medicine, King Abdulaziz Medical City, Riyadh, Ministry of National Guard-Health Affairs, Riyadh 14611, Saudi Arabia

Y. Al-Saleh · S. Sabico · N. M. Al-Daghri

Chair for Biomarkers of Chronic Diseases,

Biochemistry Department, College of Science, King

Saud University, Riyadh 11451, Saudi Arabia
D. ALROMAIHI

King Hamad University Hospital, Bahrain Medical University of Bahrain, Al Sayh, Bahrain Bahrain Diabetes Society, Manama, Bahrain

E. BA-ESSA

Dammam Medical Complex, Dammam, Saudi Arabia

F. ALAWADI and M. HASSANEIN

Endocrine Department, Dubai Hospital, Dubai Health Authority, Dubai, United Arab Emirates

J. ALKAABI

Department of Internal Medicine, College of Medicine, and Health Sciences, UAE University, Al Ain, United Arab Emirates

\section{A. Al-Furqani}

Sultan Qaboos University Hospital, Muscat, Oman

A. Jayyousi

Endocrine and Diabetes Section, Hamad Medical Corporation, Doha, Qatar
A. Jayyousi
Weill Cornell Medical College, Doha, Qatar
D. Alromaihi
King Hamad University Hospital, Busaiteen, Bahrain
D. Alromaihi
Medical University of Bahrain, Al Sayh, Bahrain
D. Alromaihi
Bahrain Diabetes Society, Manama, Bahrain 


\section{S. AL-SIFRI}

Al Hada Military Hospital, Taif, Saudi Arabia

S. SALEH

Prince Sultan Cardiac Center, Riyadh, Saudi Arabia

T. ALESSA

Division of Endocrinology, Diabetes and Metabolism, Jaber Al-Ahmad Hospital, Kuwait City, Kuwait

Dasman Diabetes Institute, Kuwait City, Kuwait

Open Access. This article is licensed under a Creative Commons Attribution-NonCommercial 4.0 International License, which permits any non-commercial use, sharing, adaptation,

E. Ba-Essa

Dammam Medical Complex, Dammam, Saudi Arabia

F. Alawadi $\cdot$ M. Hassanein

Endocrine Department, Dubai Hospital, Dubai

Health Authority, Dubai, United Arab Emirates

J. Alkaabi

Department of Internal Medicine, College of

Medicine, and Health Sciences, UAE University, Al

Ain, United Arab Emirates

S. Al-Sifri

Al Hada Military Hospital, Taif, Saudi Arabia

S. Saleh

Prince Sultan Cardiac Center, Riyadh, Saudi Arabia distribution and reproduction in any medium or format, as long as you give appropriate credit to the original author(s) and the source, provide a link to the Creative Commons licence, and indicate if changes were made. The images or other third party material in this article are included in the article's Creative Commons licence, unless indicated otherwise in a credit line to the material. If material is not included in the article's Creative Commons licence and your intended use is not permitted by statutory regulation or exceeds the permitted use, you will need to obtain permission directly from the copyright holder. To view a copy of this licence, visit http://creativecommons.org/licenses/bync/4.0/.

T. Alessa

Division of Endocrinology, Diabetes and

Metabolism, Jaber Al-Ahmad Hospital, Kuwait City, Kuwait

T. Alessa

Dasman Diabetes Institute, Kuwait City, Kuwait 